\title{
Light brown apple moth's arrival in California worries commodity groups
}

by Lucia G. Varela, Marshall W. Johnson,

Larry Strand, Cheryl A. Wilen and Carolyn Pickel

\section{Light brown apple moth is an exotic}

pest that was confirmed in California

in March 2007. It is a tortricid leaf-

roller moth native to Australia, which

has a broad range of plant hosts with

the capacity to cause damage across

a wide array of crops, natural areas

and ornamental plants. California and

federal agencies have issued quaran-

tine orders affecting production and

retail nurseries, and potentially fruit

and vegetable exports. It is found

thus far primarily in nurseries near

urban areas. Eradication efforts are

under way to prevent its spread into

California crop areas and throughout

the United States.

IN March 2007, the U.S. Department of Agriculture's Animal and Plant Health Inspection Service (APHIS) confirmed the presence of light brown apple moth (LBAM) (Epiphyas postvittana) in California, based on specimens from Alameda and Contra Costa counties. As of December 2007, a total of 15,594 male moths caught in pheromone traps had been confirmed as light brown apple moth. The largest numbers of moths are being trapped in southern Santa Cruz and northern Monterey counties. The second highest area of capture includes contiguous portions of northwest Alameda, western Contra Costa and San Francisco counties. Less than 1\% of the captures are from mostly single trap catches in Los Angeles, Marin, Napa, San Luis Obispo, San Mateo, Santa Barbara, Santa Clara, Solano and Sonoma counties (CDFA 2007c). Although light brown apple moth has been present in Hawaii since the late 1800s, this is the first time this pest has been detected in the continental United States.

Although light brown apple moth has been confirmed in 14 counties, only por-

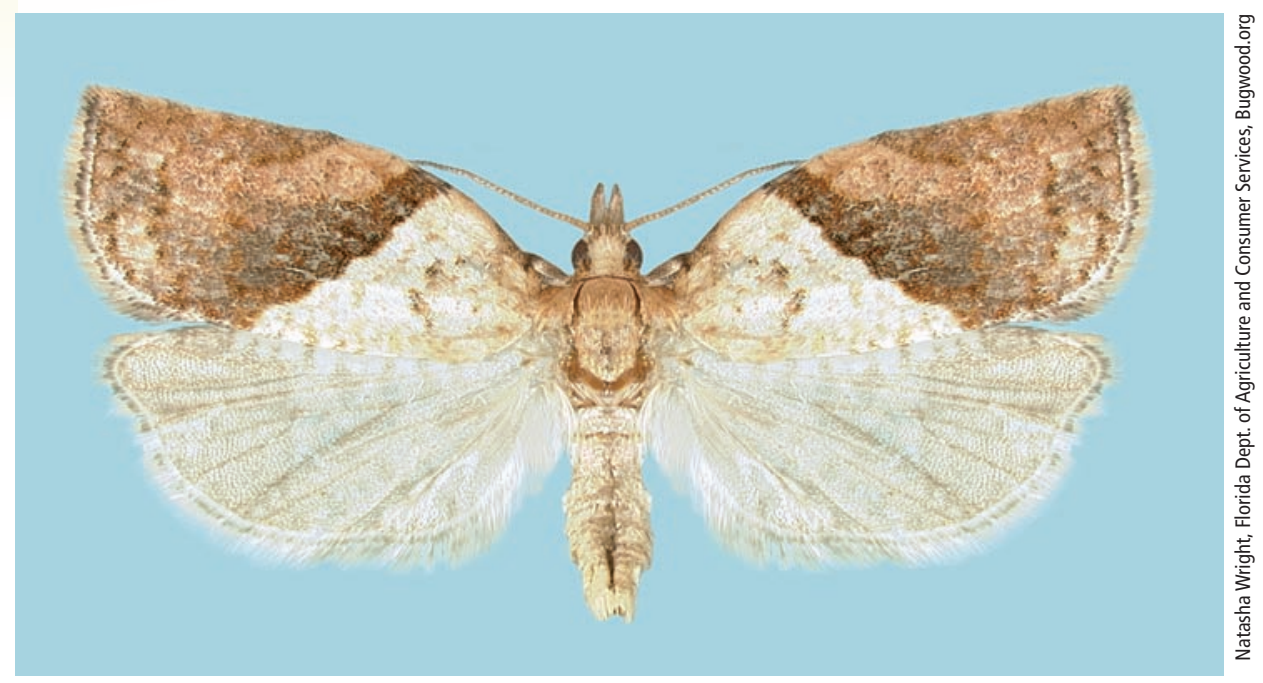

The light brown apple moth, a tortricid leafroller, is extremely variable and difficult to identify visually. The insect's reproductive organs must be examined in order to obtain a positive identification.

tions of Alameda, Contra Costa, Marin, Monterey, San Francisco, San Mateo, Santa Clara, Santa Cruz and Solano counties are currently subject to quarantine (CDFA 2007d). According to current California Department of Food and Agriculture (CDFA) regulations, a county is quarantined if specimens representing more than one life stage of the moth or a mated female are confirmed within a 3-mile radius (USDA APHIS 2007b).

The light brown apple moth is a tortricid leafroller moth native to Australia. It is now established in New Zealand, New Caledonia, the British Isles and Hawaii (Danthanarayana 1975; Suckling et al. 1998). It has a broad range of plant hosts, including herbaceous plants, landscape trees, ornamental shrubs, fruit and certain vegetable crops (Rogers et al. 2003; Wearing et al. 1991). It is known to feed on 250 plant species in over 50 families, but prefers plants in the aster (Asteraceae), legume (Fabaceae), knotweed (Polygonaceae) and rose (Rosaceae) families (CDFA 2007a).

Elsewhere, light brown apple moth has been reported as a pest on apple, pear, peach, apricot, citrus, persimmon, avocado, walnut, grape, kiwifruit, strawberry, cane berries and cole crops. It may also infest oak, willow, poplar, cottonwood, alder, pine, eucalyptus, rose, camellia, jasmine, chrysanthemum, clover, plantain and many other plants (Brockerhoff et al. 2002; Buchanan 1977). In California, larvae identified as possible light brown apple moth have been found in apples, strawberries and grapes in commercial fields. The most common hosts in nurseries and the landscape have been Prunus spp. and California wax myrtle (Myrica californica). However, an extensive survey of possible hosts has not been conducted, so these initial findings may not be representative of the types of plants likely to be infested in California. Light brown apple moth is polyphagous (able to feed on many plants). It may encounter and infest additional hosts with which it has not been previously associated.

California and U.S. federal agencies have issued orders restricting intra- and interstate shipments of plant material from quarantine counties (CDFA 2007d; USDA APHIS 2007a). At present, production and retail nurseries are the industries most affected by these regulations. Equally important are the current or potential trade restrictions on fruits and vegetables imposed by importing countries (CFIA 2007; CDFA 2007b).

\section{Identification and description}

Positive identification of light brown apple moth can be made with certainty only by examining the adult moth's re- 


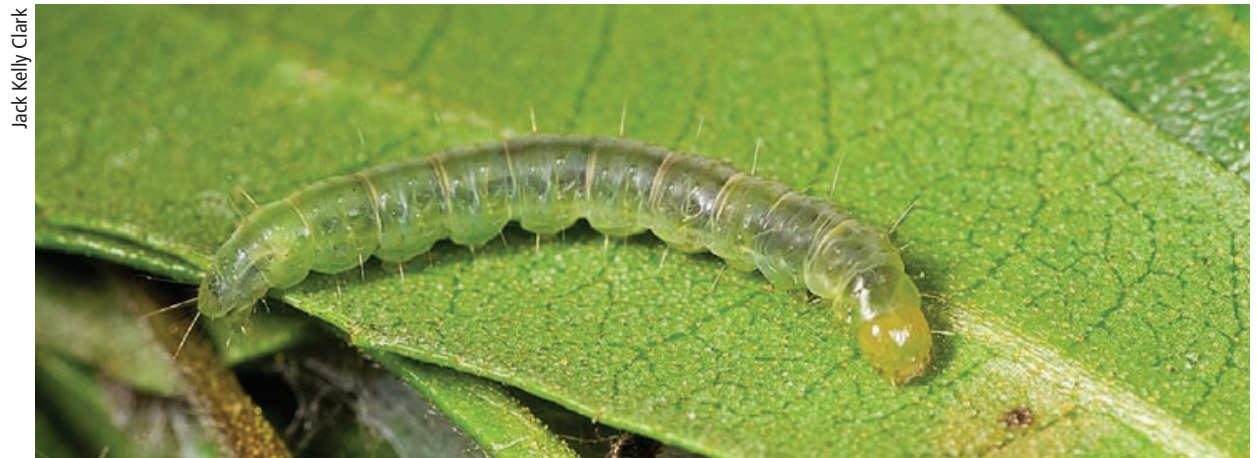

The leafroller's mature larva feeds on hundreds of different plants and agricultural crops.

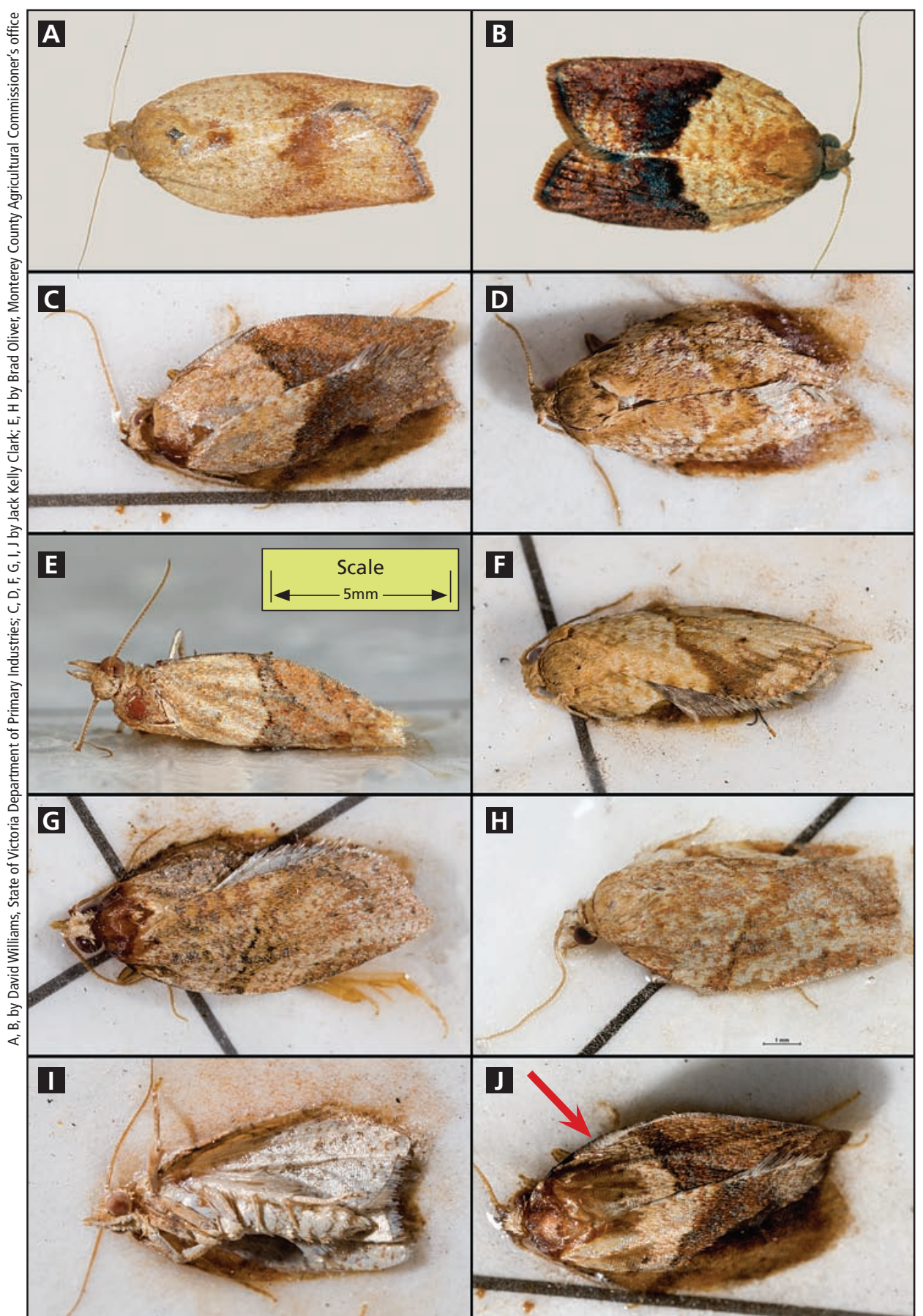

Female (A) and male (B) light brown apple moths. The wing-color pattern of light brown apple moth males (C-I) in pheromone traps can be highly variable. Males have a costal fold (arrow) on the forewing (J). productive organs (Dugdale et al. 2005; Zimmerman 1978). Growers who wish to obtain positive identification of a suspect insect should bring the live larvae, if possible still inside the webbed nest of rolled-up leaves, to their agricultural commissioner's office.

Light brown apple moth closely resembles other native California tortricids such as orange tortrix (Argyrotaenia franciscana) and garden tortrix (Clepsis peritana). Adults hold their wings over their abdomens in a bell shape when at rest, and have protruding mouthparts that resemble a snout. The antennae are simple, not featherlike. Adult size may vary during the season, with larger individuals present during cool, wet months and smaller individuals present during warm, dry months (Danthanarayana 1976).

Wings. The length of the forewing (front wing, the most obvious wing when the moth is at rest) in the female is 0.27 to 0.5 inch ( 7 to 13 millimeters) and in the male approximately 0.23 to 0.4 inch (6 to 10 millimeters) (see photos A, B). There is considerable variation in the color patterns of the wings, especially on the males (Bradley 1973). The basal half (closest to the head) of the male forewing may be light brown to pale yellow, while the distal half (farthest from the head) is reddish-brown (see photos B, C). In deeply colored forms the distal half of the forewing may vary from reddishbrown (see photo $C$ ) to blackish with purplish mottling (see photo B), and the basal half is sparsely speckled with black. In some males, the two-tone wing coloration of the forewings may be absent. Instead they are light brown with a slightly darker oblique marking (see photos D, E, F, G, H). While all color patterns of the wing have been found in males caught in California, by far the most prevalent pattern has been light brown with slightly darker oblique marking (see photos D, E, F, G, H).

In the female, forewing color varies from uniform light brown, with almost no distinguishing markings or with a dark spot in the center-front of the folded wings, to the typical oblique markings of the male, but with less contrast between the basal and distal halves (see photo A). The hindwings 
(back wing) of both sexes are pale brown to grey, either uniform in color or mottled with wavy dark-brown markings (see photo I).

Males have an extension of the "forward" outer edge of the forewing called the costal fold (see photo J), which runs from the base of the wing to two-fifths of the length of the wing edge. This is an expanded part of the wing that folds up over the front edge of the wing as a flap. Females do not have this costal fold.

Eggs. The eggs are pale yellow to light green, broadly oval and flat with a pebbled surface. They are laid slightly overlapping each other like fish scales. The egg mass is covered with a greenish transparent coating. An egg mass may contain from 2 to 170 eggs, but typically has 20 to 50 eggs. A female may lay multiple egg masses, depositing them on the upper surface of host leaves and occasionally on fruit and young stems. As the eggs develop, they change to paler yellow-green. Immediately prior to hatching, the dark head of the developing caterpillar is visible (Danthanarayana 1983).

Larvae. The newly hatched larva is pale yellow-green, 0.06 to 0.08 inch (1.5 to 2 millimeters) long and has a dark brown head. There are five to six larval instars (stages). Mature larvae range from 0.4 to 0.7 inch (10 to 18 millimeters). The head is light yellow-brown and the prothoracic shield (segment behind the head) is light greenishbrown with no dark markings. The body is medium green with a darker green central stripe that may continue to the prothoracic shield; larvae may also have darker longitudinal stripes mine if the specimens are possibly light brown apple moth. However, absolute certainty is not possible because there are still many California tortricid larvae whose morphological characters or DNA have not been studied.

Pupae. The pupa is found in a thinwalled silken cocoon, often between two leaves webbed together. It turns from green to brown as it matures and is dark reddish-brown and 0.4 to 0.6 inch (10 to 15 millimeters) long. Pupae of all tortricids are very similar in appearance (Danthanarayana 1975).

\section{Life cycle of a pest}

Light brown apple moth is found in southeastern Australia; it was introduced on the western coast, but does not survive well at high temperatures and is a more serious pest in cooler areas with mild summers (Geier and Springett 1976; Buchanan 1977; Danthanarayana et al. 1995). The pest performs best under cool conditions (mean annual temperature of approximately $56^{\circ} \mathrm{F}$ ) with moderate rainfall (approximately 29 inches annually) and moderate-high relative humidity (approximately 70\%). Hot, dry conditions may reduce populations significantly, and it is unknown whether the insect will be able to establish in locations such as the Central Valley and inland deserts of California.

A degree-day model (which predicts the moth's growth and development according to mean temperatures over time) indicates that there would most likely be two generations a year in California's Central and North Coast areas, and three or four generations a

\section{If light brown apple moth is found in fruit-production counties, the inability to export fruit to some countries may cause severe economic hardship.}

on both sides. The hairs on the body are whitish. The thoracic legs are the same color as the head, but paler, and are also unmarked. Larvae have a greenish anal comb with seven teeth - a combshaped structure at the tail end of the larva. An overwintering larva may have a darker head and prothoracic shield (Danthanarayana 1975, 1983). Larvae can be screened using morphological characters and DNA analysis to deter- year in the Central Valley and Southern California. The lower and upper developmental thresholds for light brown apple moth are $45^{\circ} \mathrm{F}$ and $88^{\circ} \mathrm{F}$, respectively (Danthanarayana 1975). Completion of the entire life cycle requires 620 degreedays above $45^{\circ} \mathrm{F}$. In Australia, New Zealand and the British Isles, generations overlap. Light brown apple moth does not have a winter resting stage (diapause). Cold winter temperatures

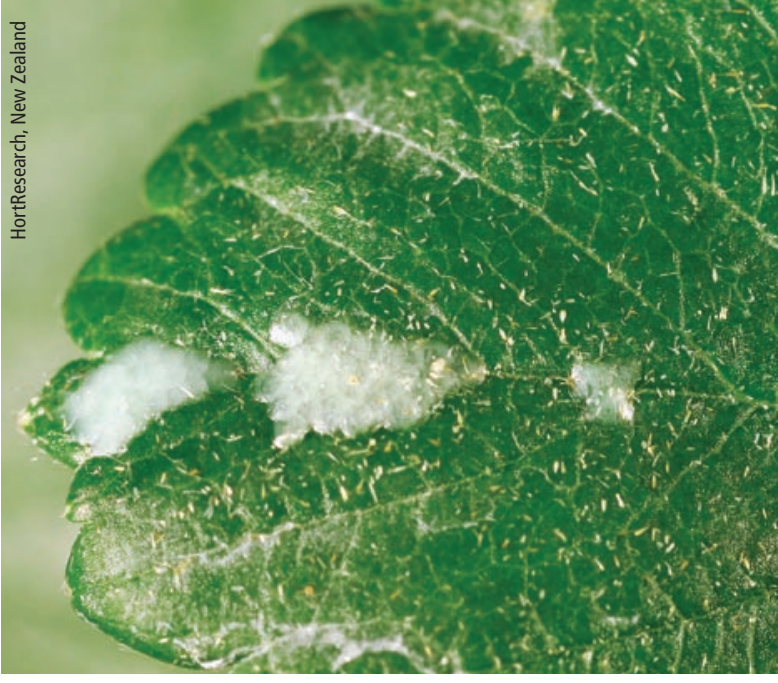

Eggs of the light brown apple moth are typically deposited on the upper surface of host leaves in masses of 20 to 50 .

slow larval development considerably (Geier and Briese 1980). Thus, the pest overwinters as second to fourth instar larvae that feed on herbaceous plants, buds of deciduous trees or shrubs, mummified fruit and other plant material. Larvae may survive for up to 2 months in the winter without feeding.

Adult moths emerge after 1 to 3 weeks of pupation and mate soon after emergence. They stay sheltered in the foliage during the day, resting on leaf undersides. Moths fly 2 to 3 hours after sunset and before daybreak. The light brown apple moth is capable of flying only short distances to find a suitable plant host (Suckling et al. 1994). Most moths fly no farther than 330 feet (100 meters), but some may fly as far as 2,000 feet (600 meters). Males disperse farther than females. Adults are less likely to leave areas with high-quality hosts. Adult life span is 2 to 3 weeks, with longevity influenced by host plant and temperature.

Females begin to lay eggs 2 to 3 days after emerging, depositing eggs at night. They prefer to deposit their eggs on smooth leaf surfaces, and usually lay a total of 120 to 500 eggs, but can lay up to 1,500 eggs (Danthanarayana 1975). An egg takes from 5 to more than 30 days to hatch, depending on temperature.

Larvae emerge from eggs after 1 to 2 weeks. Although egg masses may include 20 to 50 eggs, the resulting larvae disperse widely, each creating a nest on a separate leaf. When a larva finds a feeding site, it forms a silken shelter near the midrib on the leaf underside and begins to feed. Second and later stages feed on two to several leaves 


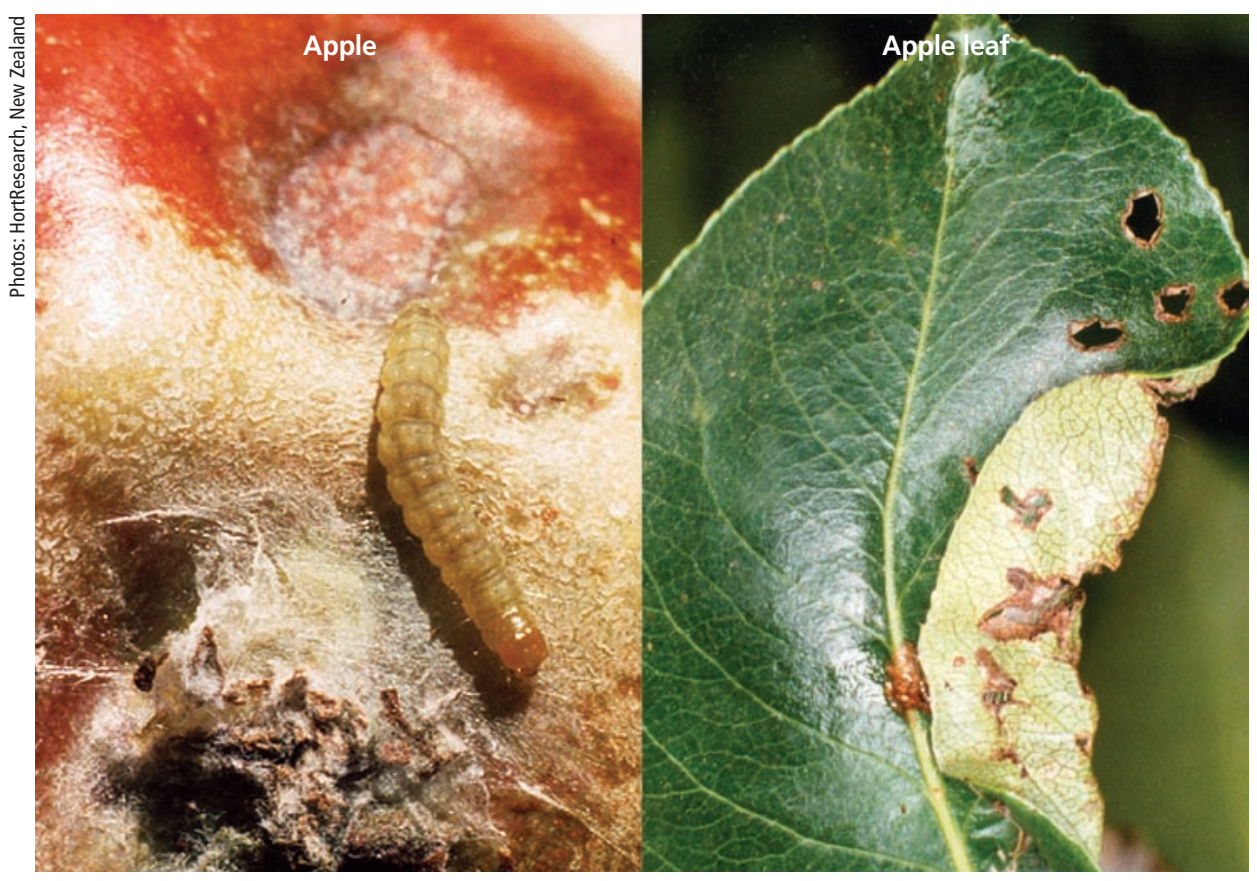

Originally from southern Australia, the light brown apple moth can feed on and damage a broad range of crops such as, above, apple. If the pest becomes established in California the most important impact to growers will likely be trade restrictions on crop exports.

webbed together, a leaf webbed to a fruit, or in the center of a fruit cluster. The larvae feed within these shelters, and they may feed on fruit when it touches a leaf. Larvae on fruit are most likely to be found near the calyx, the residual basal flower parts. When disturbed they wiggle violently, suspend themselves from a silken thread and drop to the ground, where they feed on groundcover hosts. Larval development can take from 3 to 8 weeks, depending on temperature. Pupation is completed inside the silken feeding shelter. The pupal stage lasts 1 to 3 weeks.

\section{Potential crop damage}

Like other tortricid leafrollers, light brown apple moth feeds from within the sheltering nest it constructs. Light brown apple moth has attained pest status only in southeastern Australia and New Zealand (Danthanarayana 1995). Foliar feeding is usually considered minor in fruit crops, though it might be of economic importance on nursery stock and of cosmetic importance on landscape ornamentals. On fruit crops the primary concern is fruit damage (Wearing et al. 1991; Lo et al. 2000). Larvae remove the outermost layers of the fruit surface as they feed. Superficial feeding injury to the fruit is typically caused by later immature stages. Young larvae may enter the interior of a pome fruit through the calyx. They can cause internal damage to stone fruits as well.

Minor feeding damage can take the form of pinpricks, or "stings," on the fruit surface. In grapes, larvae can cause extensive loss of flowers or newly set berries in the spring. Later in the season, grapes can be severely damaged by larvae feeding among the berries, allowing plant pathogens causing mold to enter (Buchanan 1977; Buchanan et al. 1991; Lo and Murrell 2000). In citrus, larval feeding causes fruit drop or halo scars around the stem end of the fruit. In crops such as kiwifruit, plum, citrus and pome fruit, the maturing fruit produces a layer of corky tissue over the leafroller damage. Buds of deciduous host plants are vulnerable to attack in the winter and early spring. Conifers are damaged by larval activity such as needle tying, chewing of buds and boring into stems. In tree nurseries, damage to terminal buds on seedlings and saplings can cause multiple or crooked leaders (Wearing et al. 1991).

\section{California impacts and control}

In California, light brown apple moth has been detected on agricultural lands mostly in production and retail nurseries located near urban areas. Light brown apple moth may be inadvertently moved during the transport of nursery stock. Currently the brunt of the economic cost is borne by the nursery industry in the most infested counties.

If light brown apple moth continues to spread, several vegetable and fruit crops may be affected such as apples, pears, caneberries and peppers. California growers already deal with one or more leafroller pest species on most of these crops. Management practices are available for suppressing leafrollers, and the same approaches would be used against light brown apple moth. However, the primary concern is the trade restrictions imposed by importing countries. Mexico and Canada already have restrictions on the importation of crops and plants from the infested areas of California. China has begun the information gathering that frequently leads to trade restrictions. Many countries such as Chile, Korea, Peru and South Africa list light brown apple moth as a quarantine pest and may require certification attesting that commodities such as pome fruits, grapes, citrus and stone fruits are pest-free. If light brown apple moth is found in fruit-production counties, the inability to export fruit to some countries may cause severe economic hardship to some sectors of California's agricultural industry.

APHIS has called together experts from the United States, Australia and New Zealand to form a Technical Working Group to advise on steps for managing the light brown apple moth infestation in California. APHIS and CDFA's current long-term goal is to eradicate light brown apple moth from California (see page 55). However, no single control technique currently exists that can be effectively implemented over an entire infested area. Eradication will require a multiphase approach.

Eradication will focus initially on specific localities to determine its feasibility. While eradication attempts are under way, it is important to ensure that light brown apple moth infestations do not continue to increase in size and expand to uninfested areas. Environmentally compatible methods of pest management are needed to maintain public support for the eradi- 
cation effort and to keep light brown apple moth at low numbers across agricultural, urban and natural areas.

Several reduced-risk insecticides are registered in agricultural and ornamental crops that effectively control leafrollers. These include insect growth regulators, spinosyns and Bacillus thuringiensis (Bailey et al. 1996)

In Australia, light brown apple moth has been managed in citrus, grapes and other crop systems using mating disruption (Mo et al. 2006). Light brown apple moth pheromone has two key components, both of which must be present for optimal control (Bellas et al. 1983; Suckling and Clearwater 1990). Presently, mating disruption is being implemented in some infested areas of California.

There are numerous leafroller species in California, and many of these have effective parasitoids (such as Cotesia, Exochus, Macrocentrus, Nemorilla

\section{References}

Bailey P, Baker G, Caon G. 1996. Field efficacy and persistence of Bacillus thuringiensis var. kurstaki against Epiphyas postvittana (Walker) (Lepidoptera: Tortricidae) in relation to larval behaviour on grapevine leaves. Aust J Entomol 35:297-302.

Bellas TE, Bartell RJ, Hill A. 1983. Identification of two components of the sex pheromone of the moth, Epiphyas postvittana (Lepidoptera, Tortricidae). J Chem Ecol 9:503-12.

Bradley JD. 1973. Epiphyas postvittana (Walker). In: British Tortricoid Moths. Cochylidae and Torticidae: Tortricinae. Ray Society, London. p 126-7.

Brockerhoff EG, Jactel H, Leckie AC, Suckling DM 2002. Species composition and abundance of leafrollers in a Canterbury pine plantation. NZ Plant Protect 55:85-9.

Buchanan GA. 1977. The seasonal abundance and control of light brown apple moth, Epiphyas postvittana (Walker) (Lepidoptera: Tortricidae), on grapevines in Victoria. Aust J Ag Res 28:125-32.

Buchanan GA, Stirrat SC, Madge DG. 1991. Integrated control of light brown apple moth, Epiphyas postvittana (Walker), in vineyards. Wine Ind J 6:220-2.

[CDFA] California Department of Food and Agriculture. 2007a. Light brown apple moth host list. www.cdfa.ca.gov/phpps/PDEP/target_pest_disease_ profiles/LBAM_HostList.pdf. 6 p.

CDFA. 2007b. Light brown apple moth project: Advisories. PSA No. 12-2007. www.cdfa.ca.gov/ phpps/pdep/lbam/advisories.html. 4 p

CDFA. 2007c. Light brown apple moth situation reports. www.cdfa.ca.gov/phpps/PDEP/lbam/situationreports.html. $4 \mathrm{p}$.

CDFA. 2007d. Plant Quarantine Manual: Light Brown Apple Moth State Interior Quarantine. http:// pi.cdfa.ca.gov/pqm/manual/pdf/419.pdf. 19 p.

[CFIA] Canadian Food Inspection Agency. 2007 Plant protection (phytosanitary) import requirements and Trichogramma species) and predators (such as spiders, minute pirate bugs, lacewings and Phytocoris bugs). It is highly probable that some of the California native natural enemies will expand their prey ranges to include light brown apple moth eggs, larvae and pupae. Natural enemies could also be collected in the native home of light brown apple moth and introduced into California. In Australia, as many as 25 different parasitoid species have been reared from light brown apple moths collected in the field (Charles et al. 1996; Geier and Briese 1980; Paull and Austin 2006). Imported natural enemies require extensive host specificity testing, which may take several years to ensure that they are not a threat to endangered endemic species.

Currently, light brown apple moth is found in limited areas of California. However, it has the potential to establish widely in California as well

to prevent the entry of Epiphyas postvittana (Walker) (light brown apple moth). www.inspection.gc.ca/english/plaveg/protect/dir/d-07-03e.shtml\#12c.

Charles JG, Walker JTS, White V. 1996. Leafroller phenology and parasitism in Hawkes Bay, New Zealand, canefruit gardens. NZ J Crop Hort Sci 24:123-31.

Danthanarayana W. 1975. The bionomics, distribution and host range of the light brown apple moth, Epiphyas postvittana (Walk.) (Tortricidae). Aust J Zool 23:419-37.

Danthanarayana W. 1976. Environmentally cued size variation in the light-brown apple moth, Epiphyas postvittana (Walk.) (Tortricidae), and its adaptive value in dispersal. Oecologia 26:121-32.

Danthanarayana W. 1983. Population ecology of the light brown apple moth, Epiphyas postvittana (Lepidoptera: Tortricidae). J Anim Ecol 52:1-33.

Danthanarayana W, Gu H, Ashley H. 1995. Population growth potential of Epiphyas postvittana, the lightbrown apple moth (Lepidoptera: Tortricidae) in relation to diet, temperature and climate. Aust J Zool 43:381-94.

Dugdale JS, Gleeson D, Clunie LH, Holder PW. 2005. A diagnostic guide to Tortricidae encountered in field surveys and quarantine inspections in New Zealand: Morphological and molecular characters. Ministry of Agriculture and Forestry, Wellington. $161 \mathrm{p}$.

Geier PW, Briese DT. 1980. The light-brown apple moth, Epiphyas postvittana (Walker): 4. Studies on population dynamics and injuriousness to apples in the Australian Capital Territory. Aust J Ecol 5:63-93.

Geier PW, Springett PB. 1976. Population characteristics of Australian leafrollers (Epiphyas spp., Lepidoptera) infesting orchards. Aust J Ecol 1:129-44.

Lo PL, Murrell VC. 2000. Time of leafroller infestation and effect on yield in grapes. NZ Plant Protect 53:173-8.

Lo PL, Suckling DM, Bradley SJ, et al. 2000. Factors affecting feeding site preferences of light brown apple moth, Epiphyas postvittana (Lepidoptera: Tortricidae), on apple trees in New Zealand. NZ J Crop Hort Sci 28:235-43. as other important agricultural states (such as Arizona, Texas and Florida). Although eradication from its present California distribution may seem difficult and expensive, the effort is worthwhile given the possible economic and ecological ramifications should the species establish itself and proliferate throughout agricultural acreage in California and the United States.

L.G. Varela is Integrated Pest Management (IPM) Advisor, UC Statewide IPM Program and UC Cooperative Extension (UCCE), Sonoma County; M.W. Johnson is UCCE Specialist and Entomologist, Department of Entomology, UC Riverside; L. Strand is Principal Editor, UC Statewide IPM Program; C.A. Wilen is IPM Advisor, UC Statewide IPM Program and UCCE, San Diego County; and C. Pickel is IPM Advisor, UC Statewide Program and UCCE, Sutter/Yuba Counties. The authors thank Marc Epstein, CDFA Plant Pest Diagnostics, Sacramento; Phillip Holmes, USDA/APHISIPPQ Watsonville LBAM Project; and Joyce Strand, UC Statewide IPM Program.

Mo J, Glover M, Munro S, Beattie GAC. 2006 Evaluation of mating disruption for control of lightbrown apple moth (Lepidoptera: Tortricidae) in citrus. J Econ Entomol 99:421-6.

Paull C, Austin AD. 2006. The hymenopteran parasitoids of light brown apple moth, Epiphyas postvittana (Walker) (Lepidoptera: Tortricidae) in Australia. Aust J Entomol 45:142-56.

Rogers DJ, Walker JTS, Moen IC, et al. 2003. Understorey influence on leafroller populations in Hawke's Bay organic apple orchards. NZ Plant Protect 56:168-73.

Suckling DM, Brunner JF, Burnip GM, Walker JTS. 1994. Dispersal of Epiphyas postvittana (Walker) and Planotortrix octo Dugdale (Lepidoptera: Tortricidae) at a Canterbury, New Zealand orchard. NZ J Crop Hort Sci 22:225-34.

Suckling DM, Burnip GM, Walker JTS, et al. 1998. Abundance of leafrollers and their parasitoids on selected host plants in New Zealand. NZ J Crop Hort Sci 26:193-203.

Suckling DM, Clearwater JR. 1990. Small scale trials of mating disruption of Epiphyas postvittana (Lepidoptera: Tortricidae). Environ Entomol 19:1702-9.

[USDA APHIS] US Department of Agriculture Animal and Plant Health Inspection Service. 2007a. Federal domestic quarantine order Epiphyas postvittana (light brown apple moth) DA-2007-42 www.aphis.usda.gov/plant_health/plant_pest_info/ lba_moth/downloads/federalorder-11-20-07.pdf. 5 p.

USDA APHIS. 2007b. Light Brown Apple Moth (LBAM) Regulatory Protocol. APHIS Plant Protection and Quarantine. www.aphis.usda.gov/plant_health/plant_ pest_info/lba_moth/downloads/bam-regulatoryprotocol. pdf. 2 p.

Wearing $\mathrm{CH}$, Thomas WP, Dugdale JS, Danthanarayana W. 1991. Tortricid pests of pome and stonefruits, Australian and New Zealand species. In: Tortricid Pests: Their Biology, Natural Enemies, and Control. World Crop Pests, Vol. 5. Elsevier: Amsterdam. p 453-72.

Zimmerman EC. 1978. Insects of Hawaii: Microlepidoptera. Honolulu: Univ Pr Hawaii. 1,923 p. 